\title{
Review of Weaver and Dunn on treatment of acromioclavicular injuries, especially complete acromioclavicular separation
}

\author{
Daniël E Verstift, ${ }^{1}$ Matthijs P Somford, ${ }^{2}$ Derek F P van Deurzen, ${ }^{1}$ \\ Michel P J van den Bekerom ${ }^{1}$
}

\begin{abstract}
- Additional material is published online only. To view please visit the journal online (http://dx.doi.org/10.1136/ jisakos-2019-000299)

${ }^{1}$ Department of Orthopedic Surgery and Traumatology, OLVG, Amsterdam, NoordHolland, The Netherlands ${ }^{2}$ Department of Orthopedic Surgery, Rijnstate, Arnhem, Gelderland, The Netherlands
\end{abstract}

Correspondence to Dr Daniël E Verstift, Department of Orthopedic Surgery and Traumatology, OLVG, 1090 HM Amsterdam, Noord-Holland, The Netherlands:

daniel_verstift@live.nl

Received 17 January 2020

Revised 6 July 2020

Accepted 20 July 2020

Published Online First

24 September 2020
Check for updates

(C) International Society of Arthroscopy, Knee Surgery and Orthopaedic Sports Medicine 2021. No commercial re-use. See rights and permissions. Published by BMJ.

To cite: Verstift $D E$,

Somford MP, van

Deurzen DFP, et al. J ISAKOS

2021:6:116-119.

\section{ABSTRACT}

This classic discusses the original publication

"Treatment of acromioclavicular injuries, especially complete acromioclavicular separation" by Weaver and Dunn, which collaborated to develop a technique for acromioclavicular joint reconstruction in 1972. Their surgical technique described resection of $2 \mathrm{~cm}$ of the distal clavicle and transfer of the acromial end of the coracoacromial ligament into the medullary canal of the distal clavicle. (modified) Weaver-Dunn procedures have been regarded as one of the most effective techniques to treat complete acromioclavicular joint dislocation for a long time. However, anatomic reconstructions have taken over this position since recent biomechanical studies have demonstrated superior results. Although the Weaver-Dunn procedure has fallen out of favour, it remains of historical significance. For this reason, this review will comprise the historical overview of the Weaver-Dunn procedure, the men behind the eponym and the clinical implication then and now.

\section{INTRODUCTION}

Over the past few decades, the indication for surgery for complete acromioclavicular joint injuries (Rockwood grade III-VI) has been an ongoing debate. It is still not entirely clear which patients benefit most from surgery and which do not. A subdivision for grade III injuries of the Rockwood classification was proposed (IIIA: horizontally stable; IIIB: horizontally unstable) to aid in the surgical decisionmaking. ${ }^{1}$ At this time, patients with Rockwood type IIIB-VI may benefit from surgery.

As for the optimal technique to treat acute and delayed acromioclavicular instability, no gold standard has yet been established. Over 100 techniques have been described. ${ }^{2}$ The transfer of the coracoacromial ligament from its acromial to the distal clavicle for ACJ dislocation was first described in 1917. ${ }^{3}$ In 1972 , Weaver and Dunn were the first to publish a case series with coracoacromial ligament transfer. ${ }^{4}$ Since that time, the Weaver-Dunn procedure was one of the cornerstones in the treatment of acromioclavicular separation. Recently, however, anatomical reconstructions have gained in popularity among shoulder surgeons as biomechanical results show promise. ${ }^{5-8}$ The surgical trend slowly shifts away from non-anatomical procedures and in particular the Weaver-Dunn procedure.

This review will comprise the historical overview of the Weaver-Dunn procedure, the men behind the eponym (Dr J K Weaver and Dr H K Dunn) and the clinical implication then and now. For in-depth expert opinions (Dr H K Dunn, Dr K Beitzel, Dr P $\mathrm{J}$ Millett) on this subject, see online supplementary appendix 1.

\section{The men behind the eponym}

James K Weaver ${ }^{910}$ (1929-2017) was born in Fort Collins, Colorado. He moved to Glenwood Springs, Colorado, where he spent his childhood. After graduating from high school in 1947, he attended Harvard University, where he was captain of the Harvard Ski Team. He excelled both in academics and sports. He received his medical degree from the University of Colorado Medical School in Denver, followed by a 1-year fellowship at the University of Edinburgh in Scotland. After spending several years in the military service at Elgin Air Force base, he returned to the University of Colorado as an assistant professor. Later, he joined the University of New Mexico in Albuquerque, where he would serve as Chief of the Division of Orthopaedic Surgery. Dr Weaver specialised in total joint replacement surgery, paediatric orthopaedics and sports medicine. Beyond orthopaedics, Dr Weaver loved horses and the western way of life; horse packing surveyors tasked with mapping the mountains of the Colorado Rockies. He was a member of numerous orthopaedic groups including the American Orthopaedic Society for Sports Medicine, American Academy of Orthopaedic Surgeons, Association of Bone and Joint Surgeons and the Western Orthopaedic Society, which named him President. He died on 20 September 2017.

Harold K Dunn ${ }^{11}{ }^{12}$ (1939) grew up in Artesia, New Mexico, on a cattle ranch. Riding and roping from an early age earned him a calf-roping scholarship to the New Mexico State University. After completing undergraduate studies, he attended Baylor Medical School. He married and divorced twice and had two children from the first marriage. Initially being interested in the cardiovascular surgery, serving in army participating in the Vietnam War and the time spent in a General Hospital in Japan drove Dr Dunn to become an orthopaedic surgeon. He did 1 year of general surgery residency at New Mexico finishing in 1967 where he met Dr Weaver who was in the process of starting an orthopaedic residency at New Mexico. He completed his orthopaedic residency at Baylor In 1969 and joined the faculty of the University of Utah where he would later become Chairman, which he served as for 25 years. He has three areas of special 


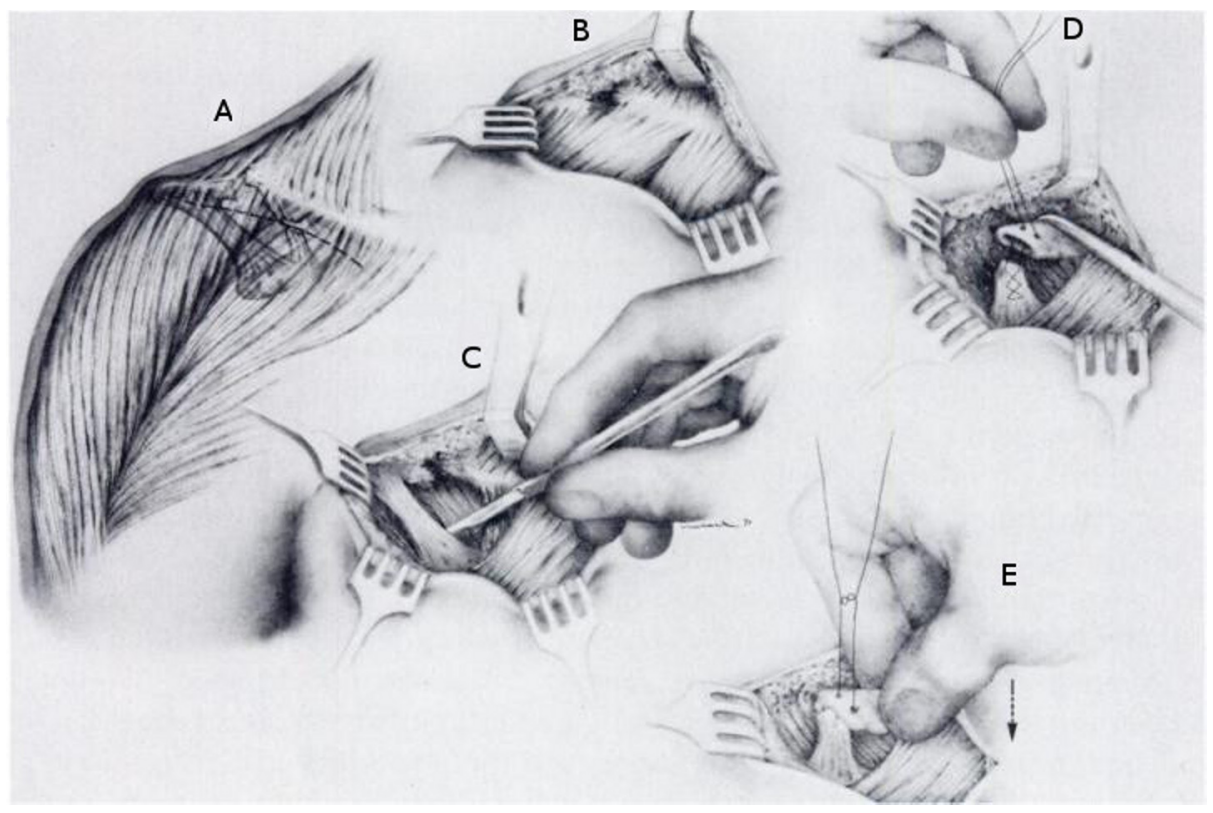

Figure 1 Weaver-Dunn procedure: (A) skin incision; (B) exposure of deltoid origin, trapezius insertion and acromioclavicular injury; (C) deltoid reflected exposing coracoacromial ligament; (D) distal $2 \mathrm{~cm}$ of clavicle resected and acromial end of coracoacromial transferred into medullary canal; (E) clavicle secured in anatomical position. Credit: Weaver JK, Dunn HK. Treatment of acromioclavicular injuries, especially complete acromioclavicular separation. J Bone Joint Surg Am 1972;54(6):1187-94.

interest, reconstruction of the adult hip and knee, scoliosis and biomechanics. His memberships include the American Academy of Orthopaedic Surgeons, Director of the American Board of Orthopaedic Surgeons, the American Orthopedic Association, American Association of Hip and Knee Surgeons, the Scoliosis Research Society and the Western Orthopedic Association.

\section{The original}

Dr Weaver and Dr Dunn collaborated to develop a technique for acromioclavicular joint reconstruction, which they published in 1972 in the Journal of Bone and Joint Surgery. ${ }^{4}$ The targeted population for this procedure were patients with complete acromioclavicular joint dislocation, classified as type III according to the Tossy and Allman classification. Type III consists of acromioclavicular separation with disruption of the coracoclavicular ligaments as well as of the acromioclavicular ligaments, leaving the clavicle grossly unstable. Dr Weaver and Dr Dunn thought that non-operative means to treat type III acromioclavicular dislocation in a general population was unsuccessful because of non-compliance during rehabilitation, non-effective reduction by tape or bandage, complications like skin maceration, tape irritation and pressure sores and joint stiffness of the shoulder. Therefore, surgery was recommended. A new approach was justified according to Dr Weaver and Dr Dunn because many difficulties with the then-existing procedures continued to be encountered. Difficulties concerned migration or failure of metallic fixation devices, erosion of the bone by fixation devices, recurrence of deformity, development of arthralgia and the need for subsequent surgeries to remove fixation devices.

Their surgical technique (see figure 1) described resection of $2 \mathrm{~cm}$ of the distal clavicle in an oblique fashion and transfer of the acromial end of the coracoacromial ligament into the medullary canal of the distal clavicle. The clavicle is held in an anatomical position relative to the coracoid and with traction applied to the coracoacromial ligament the proper length of the ligament is selected to maintain the reduction. The coracoacromial ligament is secured superiorly into the medullary canal with non-absorbable sutures to restore the stabilising effects of the torn coracoclavicular ligaments. The arm is then immobilised and circumduction exercises are advised from the first postoperative day. After 4 weeks, active range of motion is allowed.

This technique was applied to 15 patients, 12 of which were acute injuries and 3 were chronic. Good results were obtained in 11 patients, 3 results were rates as fair and 1 as poor. There was no correlation between the chronicity of the injury and the outcome after surgery. In the three patients rated as fair, there was incomplete reduction of the clavicular deformity. However, these three patients had no symptoms of pain, weakness or loss of motion.

\section{The clinical implication}

The original Weaver-Dunn procedure versus modified Weaver-Dunn procedures

Since the introduction of the Weaver-Dunn procedure, many orthopaedic surgeons introduced a modified version of the technique. Additional fixation methods to coracoacromial ligament transfer were used to help stabilise the distal clavicle, especially in the early rehabilitation period. In the early days, transfer of the coracoacromial ligament was mainly supported by fixation of the clavicle to the coracoid using lag screws (eg, Bosworth screw), ${ }^{13}{ }^{14}$ Kirschner wires, ${ }^{15} 16$ hook plates ${ }^{17-19}$ or coracoclavicular cerclage. ${ }^{1620-27}$ Due to frequent complications and hardware failure, more advanced techniques were introduced such as cortical buttons (eg, TightRope), ${ }^{16}$ 28-32 muscle transfer (eg, lateral half of the conjoined tendon), ${ }^{33-36}$ synthetic graft fixation (eg, Surgilic) ${ }^{37}$ or with autografts or allografts (eg, semitendinosus graft). ${ }^{38-40}$ Some authors focused on the coracoclavicular ligaments and on the acromioclavicular ligaments and the improvement of posterior-anterior stability after acromioclavicular capsuloligamentous reconstruction. ${ }^{4142}$

In 2004, Deshmukh et $a l^{43}$ proved biomechanically that supplemental augmentative methods are superior to the WeaverDunn reconstruction alone in terms of acromioclavicular 
stability. This was confirmed by Wilson $e t a l^{44}$ and Wellmann et $a l^{45}$ in terms of higher load to failure of augmented WeaverDunn reconstructions. In this period, Jones et $a l^{38}$ and LaPrade and Hilger ${ }^{39}$ started the now popular use of semitendinosus grafts for coracoclavicular fixation, initially as supplemental fixation to coracoacromial ligament transfer.

(modified) Weaver-Dunn versus anatomic reconstruction techniques (modified) Weaver-Dunn procedures were regarded as one of the most effective techniques to treat complete acromioclavicular joint dislocation for a long time. Since the early 2000s, there has been increasing interest in anatomical reconstructions. This was due to the suboptimal functional results and the concerns with the failure rates of modified Weaver-Dunn procedures. Recent biomechanical studies have demonstrated superior results with anatomic reconstruction of the coracoclavicular ligaments using autografts or allografts, and thus, modified Weaver-Dunn procedures have fallen out of favour. ${ }^{5-8}$

Lee $e t a l^{46}$ were one of the first to study the biomechanical properties of tendon grafts when compared with coracoclavicular ligament transfer and native ligaments. They found that when fixating the tendon grafts with double knots looped under the coracoid, the strength and stiffness of the grafts (semitendinosus, gracilis or long toe extensor tendon grafts) were similar to that of the native ligaments. Shortly after that, in 2009, Tauber $e t a l^{47}$ showed that besides superior biomechanical results of semitendinosus tendon graft for coracoclavicular ligament reconstruction compared with a modified Weaver-Dunn procedure, clinical and radiological outcomes were significantly superior as well. The promise of free grafts in surgery for acromioclavicular surgery resulted in many biomechanical and clinical studies, all investigating different grafts and fixation techniques. ${ }^{5-8} 26324148-52$

In recent systematic reviews discussing a variety of common surgical techniques including the Weaver-Dunn procedure, improved subjective patient-reported outcomes after surgical treatment of acromioclavicular joint instability were reported for coracoclavicular ligament reconstruction with a free tendon graft, reconstruction of the coracoclavicular ligaments using suspensory devices, reconstruction of the coracoclavicular ligaments using synthetic ligament devices and coracoacromial ligament transfer according to a (modified) Weaver-Dunn procedure. However, free graft reconstruction provided the highest subjective scores and fewest complications, whereas modified Weaver-Dunn procedures had the highest unplanned reoperation rates. ${ }^{253}{ }^{54}$ Nowadays, many shoulder surgeons have come to the realisation that anatomical reconstructions consistently show significantly better clinical, functional and radiological outcomes with lower radiological failure rates, especially when compared with the Weaver-Dunn procedure.

Although anatomic reconstructions for the treatment of complete acromioclavicular joint dislocation are gaining in popularity among orthopaedic surgeons, still some areas of controversy remain. There is an ongoing debate on operative versus non-operative management of complete acromioclavicular dislocation. In a meta-analysis by Tang et al, comparing surgical and conservative treatment of Rockwood type III acromioclavicular dislocation, no significant differences in functional outcome were found. ${ }^{55}$ Other authors present similar findings for patients with Rockwood type III, IV and V injuries. ${ }^{56-58}$ Murray et al, comparing open reduction and tunnelled suspensory device with non-operative treatment in Rockwood III and V, states that patients treated conservatively generally recover faster, although a substantial part remain dissatisfied and require delayed surgical reconstruction.

When surgery is indicated, consensus is yet to be reached regarding optimal surgical technique and indication for biological or synthetic grafts, though recent literature suggests the use of tendon grafts in chronic cases to enhance healing of the native ligaments. 5459

Overall, anatomic reconstruction techniques for complete acromioclavicular dislocation have led to modified Weaver-Dunn procedures being somewhat redundant, though of historical significance. Nevertheless, a golden standard for the treatment of these injuries covering all the areas of controversy has yet to be agreed on.

Contributors DEV wrote the manuscript. DvP helped to get in contact with the experts. MS and MPJvdB supervised the project. All authors discussed the results and contributed to the final manuscript.

Funding The authors have not declared a specific grant for this research from any funding agency in the public, commercial or not-for-profit sectors.

Competing interests None declared.

Patient consent for publication Not required.

Provenance and peer review Commissioned; externally peer reviewed.

\section{REFERENCES}

1 Beitzel K, Mazzocca AD, Bak K, et al. ISAKOS upper extremity committee consensus statement on the need for diversification of the Rockwood classification for acromioclavicular joint injuries. Arthroscopy 2014;30:271-8.

2 Xará-Leite F, Andrade R, Moreira PS, et al. Anatomic and non-anatomic reconstruction improves post-operative outcomes in chronic acromioclavicular instability: a systematic review. Knee Surg Sports Traumatol Arthrosc 2019;27:3779-96.

3 Cadenat $F$. The treatment of dislocations and fractures of the outer end of the clavicle. Int Clin 1917;1:145-69.

4 Weaver JK, Dunn HK. Treatment of acromioclavicular injuries, especially complete acromioclavicular separation. J Bone Joint Surg Am 1972;54:1187-94

5 Mazzocca AD, Santangelo SA, Johnson ST, et al. A biomechanical evaluation of an anatomical coracoclavicular ligament reconstruction. Am J Sports Med 2006:34:236-46.

6 Thomas K, Litsky A, Jones G, et al. Biomechanical comparison of coracoclavicular reconstructive techniques. Am J Sports Med 2011;39:804-10.

7 Beitzel K, Obopilwe E, Chowaniec DM, et al. Biomechanical comparison of arthroscopic repairs for acromioclavicular joint instability: suture button systems without biological augmentation. Am J Sports Med 2011;39:2218-25.

8 Li Q, Hsueh P-ling, Chen Y-feng. Coracoclavicular ligament reconstruction: a systematic review and a biomechanical study of a triple endobutton technique. Medicine 2014;93:e193.

9 The Aspen Times, 2017. Obituaries, James Kilburn weaver, M.D. Available: https:// www.aspentimes.com/obituaries/james-kilburn-weaver-m-d/

10 Calabro A. A personal remembrance of James K. weaver MD (1929-2017). Clin Orthop Relat Res 2018;476:914-6.

11 University of Utah School of Medicine, 2014. Faculty details, Dunn HK. Available: https://medicine.utah.edu/faculty/mddetail.php?facultylD=u0031473

12 Villacis DC, Popkin CA, Nowell JA, et al. Standing tall on their shoulders: essential eponyms in shoulder surgery. Journal of Shoulder and Elbow Arthroplasty 2018;2:247154921879772.

13 Guy DK, Wirth MA, Griffin JL, et al. Reconstruction of chronic and complete dislocations of the acromioclavicular joint. Clin Orthop Relat Res 1998;347:138-49.

14 Pavlik A, Csépai D, Hidas P. Surgical treatment of chronic acromioclavicular joint dislocation by modified Weaver-Dunn procedure. Knee Surg Sports Traumatol Arthrosc 2001;9:307-12.

15 Dumontier C, Sautet A, Man M, et al. Acromioclavicular dislocations: treatment by coracoacromial ligamentoplasty. J Shoulder Elbow Surg 1995;4:130-4.

16 López-Alameda S, Fernández-Santás T, García-Villanueva A, et al. Results of surgical treatment of acromioclavicular dislocations type III using modified weaver Dunn technique. Rev Esp Cir Ortop Traumatol 2018;62:93-9.

17 Faraj AA, Ketzer B. The use of a hook-plate in the management of acromioclavicular injuries. Report of ten cases. Acta Orthop Belg 2001;67:448-51.

18 Liu H-H, Chou Y-J, Chen C-H, et al. Surgical treatment of acute acromioclavicular joint injuries using a modified Weaver-Dunn procedure and clavicular hook plate. Orthopedics 2010;33. doi:10.3928/01477447-20100625-10. [Epub ahead of print: 11 Aug 2010]. 
19 Boström Windhamre HA, von Heideken JP, Une-Larsson VE, et al. Surgical treatment of chronic acromioclavicular dislocations: a comparative study of Weaver-Dunn augmented with PDS-braid or hook plate. J Shoulder Elbow Surg 2010;19:1040-8.

20 Weinstein DM, McCann PD, Mcllveen SJ, et al. Surgical treatment of complete acromioclavicular dislocations. Am J Sports Med 1995;23:324-31.

21 Tienen TG, Oyen JFCH, Eggen PJGM. A modified technique of reconstruction for complete acromioclavicular dislocation: a prospective study. Am J Sports Med 2003;31:655-9.

22 Rokito AS, Oh YH, Zuckerman JD. Modified weaver-dunn procedure for acromioclavicular joint dislocations. Orthopedics 2004;27:21-8.

23 Adam FF, Farouk O. Surgical treatment of chronic complete acromioclavicular dislocation. Int Orthop 2004;28:119-22.

24 Kumar S, Penematsa SR, Selvan T. Surgical reconstruction for chronic painful acromioclavicular joint dislocations. Arch Orthop Trauma Surg 2007;127:481-4.

25 Bezer M, Saygi B, Aydin N, et al. Quantification of acromioclavicular reduction parameters after the weaver-dunn procedure. Arch Orthop Trauma Surg 2009;129:1017-24.

26 Kumar V, Garg S, Elzein I, et al. Modified weaver-dunn procedure versus the use of a synthetic ligament for acromioclavicular joint reconstruction. J Orthop Surg 2014;22:199-203.

27 Gupta R, Sood M, Malhotra A, et al. Functional outcome of modified weaver Dunn technique for acromioclavicular joint dislocation. Indian J Orthop 2018;52:418-22.

28 Boileau P, Old J, Gastaud O, et al. All-arthroscopic weaver-dunn-chuinard procedure with double-button fixation for chronic acromioclavicular joint dislocation. Arthroscopy 2010;26:149-60

29 Zooker CC, Parks BG, White KL, et al. Tightrope versus fiber mesh tape augmentation of acromioclavicular joint reconstruction: a biomechanical study. Am J Sports Med 2010;38:1204-8.

30 Al-Ahaideb A. Surgical treatment of chronic acromioclavicular joint dislocation using the Weaver-Dunn procedure augmented by the TightRope $®$ system. Eur J Orthop Surg Traumatol 2014;24:741-5.

31 Boutsiadis A, Baverel L, Lenoir H, et al. Arthroscopic-assisted acromioclavicular and Coracoclavicular ligaments reconstruction for chronic acromioclavicular dislocations: surgical technique. Tech Hand Up Extrem Surg 2016;20:172-8.

32 Kocaoglu B, Ulku TK, Gereli A, et al. Palmaris longus tendon graft versus modified Weaver-Dunn procedure via dynamic button system for acromioclavicular joint reconstruction in chronic cases. J Shoulder Elbow Surg 2017;26:1546-52.

33 Jiang C, Wang M, Rong G. Proximally based conjoined tendon transfer for coracoclavicular reconstruction in the treatment of acromioclavicular dislocation. J Bone Joint Surg Am 2007;89:2408-12.

$34 \mathrm{Kim} \mathrm{SH}$, Lee YH, Shin SH, et al. Outcome of conjoined tendon and coracoacromial ligament transfer for the treatment of chronic type $\mathrm{V}$ acromioclavicular joint separation. Injury 2012;43:213-8.

35 Lee SK, Song DG, Choy WS. Anatomical double-bundle coracoclavicular reconstruction in chronic acromioclavicular dislocation. Orthopedics 2015;38:e655-62.

36 Le Hanneur M, Delgrande D, Lafosse T, et al. Triple-bundle anatomical reconstruction using the coracoacromial ligament and the short head of biceps tendon to stabilize chronic acromioclavicular joint dislocations: a cadaver feasibility study. Orthop Traumato/ Surg Res 2018;104:27-32.

37 Wood TA, Rosell PAE, Clasper JC. Preliminary results of the 'Surgilig' synthetic ligament in the management of chronic acromioclavicular joint disruption. J R Army Med Corps 2009;155:191-3.

38 Jones HP, Lemos MJ, Schepsis AA. Salvage of failed acromioclavicular joint reconstruction using autogenous semitendinosus tendon from the knee. surgical technique and case report. Am J Sports Med 2001;29:234-7.

39 LaPrade RF, Hilger B. Coracoclavicular ligament reconstruction using a semitendinosus graft for failed acromioclavicular separation surgery. Arthroscopy 2005;21:1277. e1-1277.e5.
40 Spencer HT, Hsu L, Sodl J, et al. Radiographic failure and rates of re-operation after acromioclavicular joint reconstruction: a comparison of surgical techniques. Bone Joint J 2016;98-B:512-8

41 Grutter PW, Petersen SA. Anatomical acromioclavicular ligament reconstruction: a biomechanical comparison of reconstructive techniques of the acromioclavicular joint. Am J Sports Med 2005;33:1723-8.

42 Luis GE, Yong C-K, Singh DA, et al. Acromioclavicular joint dislocation: a comparative biomechanical study of the palmaris-longus tendon graft reconstruction with other augmentative methods in cadaveric models. J Orthop Surg Res 2007;2:22.

43 Deshmukh AV, Wilson DR, Zilberfarb JL, et al. Stability of acromioclavicular joint reconstruction: biomechanical testing of various surgical techniques in a cadaveric model. Am J Sports Med 2004;32:1492-8.

44 Wilson DR, Moses JM, Zilberfarb JL, et al. Mechanics of coracoacromial ligament transfer augmentation for acromioclavicular joint injuries. J Biomech 2005;38:615-9.

45 Wellmann M, Lodde I, Schanz S, et al. Biomechanical evaluation of an augmented coracoacromial ligament transfer for acromioclavicular joint instability. Arthroscopy 2008;24:1395-401.

46 Lee SJ, Nicholas SJ, Akizuki KH, et al. Reconstruction of the coracoclavicular ligaments with tendon grafts: a comparative biomechanical study. Am J Sports Med 2003;31:648-55

47 Tauber M, Gordon K, Koller H, et al. Semitendinosus tendon graft versus a modified Weaver-Dunn procedure for acromioclavicular joint reconstruction in chronic cases: a prospective comparative study. Am J Sports Med 2009;37:181-90.

48 Michlitsch MG, Adamson GJ, Pink M, et al. Biomechanical comparison of a modified weaver-dunn and a free-tissue graft reconstruction of the acromioclavicular joint complex. Am J Sports Med 2010;38:1196-203.

49 Beitzel K, Obopilwe E, Chowaniec DM, et al. Biomechanical properties of repairs for dislocated $A C$ joints using suture button systems with integrated tendon augmentation. Knee Surg Sports Traumatol Arthrosc 2012;20:1931-8.

$50 \mathrm{Li} F \mathrm{~F}$, Jiang CY, Lu Y, et al. [Arthroscopic coracoclavicular ligament reconstruction versus open modified Weaver-Dunn procedure for acromioclavicular joint dislocations:comparison of curative effect]. Beijing Da Xue Xue Bao Yi Xue Ban 2015;47:253-7.

51 Hegazy G, Safwat H, Seddik M, et al. Modified weaver-dunn procedure versus the use of semitendinosus autogenous tendon graft for acromioclavicular joint reconstruction. Open Orthop J 2016;10:166-78.

52 Le Hanneur M, Thoreson A, Delgrande D, et al. Biomechanical comparison of anatomic and extra-anatomic reconstruction techniques using local grafts for chronic instability of the acromioclavicular joint. Am J Sports Med 2018;46:1927-35.

53 Moatshe G, Kruckeberg BM, Chahla J, et al. Acromioclavicular and Coracoclavicular ligament reconstruction for acromioclavicular joint instability: a systematic review of clinical and radiographic outcomes. Arthroscopy 2018;34:1979-95.

54 Borbas P, Churchill J, Ek ET. Surgical management of chronic high-grade acromioclavicular joint dislocations: a systematic review. J Shoulder Elbow Surg 2019;28:2031-8

55 Tang G, Zhang Y, Liu Y, et al. Comparison of surgical and conservative treatment of rockwood type-III acromioclavicular dislocation: a meta-analysis. Medicine 2018;97:e9690.

56 Joukainen A, Kröger H, Niemitukia L, et al. Results of operative and nonoperative treatment of rockwood types III and V acromioclavicular joint dislocation: a prospective, randomized trial with an 18- to 20-year follow-up. Orthop J Sports Med 2014; 2:2325967114560130.

$57 \mathrm{Krul} \mathrm{KP}$, Cook JB, Ku J, et al. Successful conservative therapy in rockwood type V acromioclavicular dislocations. Orthop J Sports Med 2015;3:2325967115S0001.

58 Murray IR, Robinson PG, Goudie EB, et al. Open reduction and tunneled suspensory device fixation compared with Nonoperative treatment for type-III and type-IV acromioclavicular joint dislocations: the acorn prospective, randomized controlled trial J Bone Joint Surg Am 2018;100:1912-8.

59 Phadke A, Bakti N, Bawale R, et al. Current concepts in management of ACJ injuries. J Clin Orthop Trauma 2019;10:480-5. 